\title{
On the variations of InSAR-ICA altitudes in a mountain area of the Sele Valley (South Italy)
}

\author{
Paola Ballatore \\ Mediterranean Agency for Remote Sensing and Environmental Control (MARSec), Benevento, Italy
}

\begin{abstract}
The ERS-1/ERS-2 Synthetic Aperture Radar (SAR) data are processed by InSAR-ICA technique and the altitude variations are calculated for the period June-December 1995. For the same period and the same ERS1/ERS-2 SAR data, the nominal surface deformations are calculated by the standard DInSAR (Differential Interferometric SAR) method, considered without any atmospheric correction. The results of the two different processing techniques are qualitatively compared with the previous geological and hydrological observations of the area under study. It is shown how the InSAR-ICA altitude variations are in better agreement with the expected characterization of this region. Although these variations cannot be considered quantitative precise surface deformations at present, this finding is interpreted in terms of usefulness and reliability of InSAR-ICA altitude estimations
\end{abstract}

Key words Synthetic Aperture Radar interferometry - Independent Component Analysis - ground deformations - landslides - subsidences

\section{Introduction}

The ICA (Independent Component Analysis) technique is devised for separating signals obtained as a mixture of additive components with unknown mixing coefficients (e.g., Hyvärinen et al., 2001). More specifically, ICA algorithms are applied on a vector $X$ of $n$ experimental observations $\left(x_{1}, x_{2}, \ldots, x_{\mathrm{n}}\right)$, given by the overlapping of $m$ different unknown signals $\left(s_{1}\right.$, $\left.s_{2}, \ldots, s_{\mathrm{m}}\right)$, or «sources», which are considered

Mailing address: Dr. Paola Ballatore, Mediterranean Agency for Remote Sensing and Environmental Control (MARSec), Villa dei Papi, Via Perlingieri 1, 82100 Benevento, Italy; e-mail: paolab@marsdb.it elements of a vector $S$, named the «vector of sources». The coefficients of the «mixing», $a_{i j}$, are considered the element of the matrix $A$, named «mixing matrix»:

$$
\mathrm{X}=\mathrm{A} \cdot \mathrm{S}
$$

Given $X$, when the elements of $S$ and of $A$ are unknown, ICA algorithms are devised to extract the best estimate of $A$ and $S$, defined as a minus of an additional and multiplicative constant (Hyvärinen et al., 2001).

In the case of SAR interferograms $\delta \phi_{i}$, their phases for their $n$ pixels (ordered in sequence of columns or rows) can be considered as one observation $x_{i}$ :

$$
x_{i}=\delta \phi_{i}=\left(\delta \phi_{i}{ }^{1}, \delta \phi_{i}{ }^{2}, \ldots, \delta \phi_{i}{ }^{n}\right)
$$

In this way, an array of $k$ interferograms can be considered as the columns of a matrix that can be treated as the vector of observation $X$ :

$$
X=\left(x_{1}, x_{2}, \ldots, x_{k}\right)=\left(\delta \phi_{1}, \delta \phi_{2}, \ldots, \delta \phi_{k}\right)
$$


Each $\delta \phi_{i}$ is given by the overlapping of phase shift components driven by different phenomena, such as the topographical altitude $\left(\delta \phi_{\text {topo }}\right)$, the surface deformations $\left(\delta \phi_{d e f}\right)$, the atmospheric artifacts $\left(\delta \phi_{a t m}\right)$ and generic noise $\left(\delta \phi_{\text {noise }}\right)$ :

$$
\delta \phi_{i}=\delta \phi_{\text {topo }, i}+\delta \phi_{\text {def }, i}+\delta \phi_{a t m, i}+\delta \phi_{\text {noise }, i}
$$

Also other phenomena (e.g., orbital precision, unwrapping, etc.) can drive minor phase shifts and can appear in $\delta \phi_{i}$ (Hanssen, 2001), but these can be neglected in the first instance or in specific observational circumstances. In eq. 1.4, each component can be considered due to a part common to the other interferograms $\left(s_{t o p o}, s_{\text {def }}, s_{\text {atm }}\right.$, etc $)$, multiplied by coefficients, $a_{i j}$, depending on the specific interferogram. The common parts can be considered elements of the vector of sources (taken in sequence of columns or rows, similarly to $X$ ); the $a_{i j}$ can be considered elements of the matrix $A$.

$$
\begin{aligned}
& X=\left(\delta \phi_{1}, \delta \phi_{2}, \ldots, \delta \phi_{\mathrm{k}}\right)= \\
& =A \cdot S=A \cdot\left(s_{\text {topo }}, s_{\text {def }}, s_{\text {atm }}, \ldots\right)
\end{aligned}
$$

In this way, the identification of the different components of InSAR phase shifts can be successfully represented by the typical ICA problem solving, given in eq. 1.1 (Ballatore, 2006).

In the case of SAR interferograms, the specific FastICA algorithm (e.g., Hyvärinen and Oja, 1997) was previously employed in InSARICA method (Ballatore 2006; 2007).

After FastICA application on arrays of SAR interferograms, a different post-processing is necessary to pass from each source to the corresponding geophysical parameter. In particular, this post-processing has been devised for extraction of topographical altitudes, which resulted in good agreement with the standard SRTM-DTED (Shuttle Radar Topography Mission - Digital Terrain Elevation Data) in specific test sub-areas (Ballatore, 2006; 2007).

For different SAR data sets, an extensive comparison between SRTM and InSAR-ICA altitudes has demonstrated that the distribution of the residuals is centered more or less close to zero (within the nominal errors), with distributions whose standard deviations depend on the specific interferograms considered (Ballatore, 2009). In general, an agreement between InSAR-ICA DEMs and SRTM altitudes is observed, after consideration of the criticality of SRTM measurements in the high-relief terrains (Falorni et al., 2005).

This paper addresses the differences between InSAR-ICA DEMs extracted from timeseparated interferograms arrays. Here, these are not considered precise surface deformations (because not validated to date). However, the accuracy of this parameter as a more or less rough indication of surface deformations is qualitatively investigated in one particular case to highlighting elements on the correctness of InSAR-ICA DEMs and motivating any future works on processing their differences to extract information on terrain surface deformations.

\section{The area under study}

The area considered here is a part of the Sele valley and is illustrated in fig. 1, where the river flows near the SS91 at the central vertical location. This is a basin that is a tectonically active valley of South Italy, with typical slope instabilities and floods. The altitude changes are significant: the maximum elevations reach values $>1400 \mathrm{~m}$ on the right and left sides and the minimum elevations reach about $150 \mathrm{~m}$ along the Sele river, passing through about 580 $\mathrm{m}$ a.s.l. at Senerchia and $590 \mathrm{~m}$ a.s.1. at Colliano.

The soil of this region is characterized by different lithotypes (Polemio and Petrucci, 2001; Wasowski et al., 2002). In particular, investigations around the Sele river after the 1980 earthquake indicate higher concentration of landslides on the western than on the eastern slopes of the valley (Agnesi et al., 1983; Carrara et al., 1986).

In particular, hydrological studies also illustrate a substantial difference between the eastern and western sides of the valley: many more springs are located on the western side, with higher discharges, exceeding $50 \mathrm{l} / \mathrm{s}$ in a few cases (Budetta et al., 1988, and references 


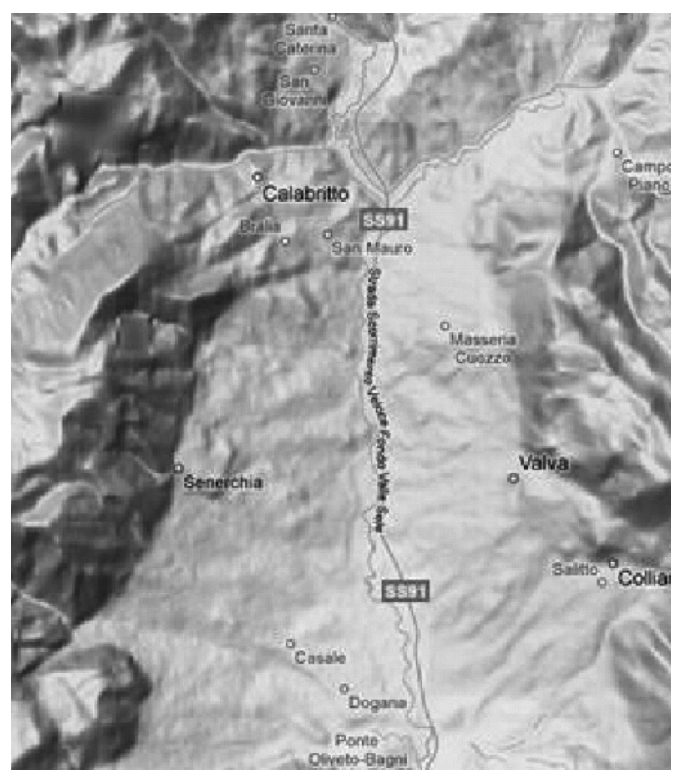

Fig. 1. Area under study with indication of the Sele river location near the SS91.

therein). Some major landslides were monitored and found active (with decrease in activity) until 2001 (e.g., Polemio and Petrucci, 2001; and references therein).

Because of the public availability of information on its peculiar terrain characterization, this area was chosen for qualitative comparison between InSAR DEM variations and the ground based geological/hydrological observations.

\section{SAR Data and Data Processing}

ERS-1 and ERS-2 Tandem data with track n. 265 and frame n. 2781 for the period from June to December 1995 were processed by InSAR-ICA and DInSAR methods.

The InSAR-ICA (Ballatore, 2007) was separately applied on two arrays of interferograms, considering ERS-TANDEM couples of images acquired on: (A) June 2 and 3, July 7 and 8, August 11 and 12, 1995; (B) October 20 and 21, November 24 and 25, December 29 and 30,
1995. The differences between the DEMs extracted from the interferograms array $\mathrm{A}$ and $\mathrm{B}$ were calculated and the interval between the maximum (positive value) and minimum (negative value) differences divided into five subranges (about equal among themselves) that are shown in different gray level in fig. 2 for about the same zone of Sele Valley shown in fig. 1. The black areas of fig. 2 correspond to the largest nominal subsidences, while the white areas correspond to the nominal uplifts.

By considering the same ERS images specified above and acquired on June 2 and 3 and on December 30, the standard three-pass DInSAR technique (e.g., Hanssen, 2001) was applied for estimating the nominal surface deformations during the same period June-December 1995. The DInSAR nominal surface deformations are shown in fig. 3 for the same area of fig. 2. Similar to fig. 2, fig. 3 shows a different gray scale level for each one of the five intervals of values between the maximum and the minimum phase differences, with black corresponding to maximum nominal subsidences and white to the maximum nominal uplifts.

The comparison between figs. 2 and 3 indicates that, according to InSAR-ICA DEMs differences, the maximum nominal subsidences are located mostly on the left of the Sele river, whereas this is not so for the DInSAR results.

It is worth mentioning that, in this processing, the DInSAR method does not include atmospheric or spurious artifacts correction, which can be subsequently executed depending on user choice/methodology. In particular, by appropriate sorting of images with especially small atmospheric artifacts or specific choice of baselines or specific case by case processing, the three-pass DInSAR method is proven to give valuable and validated results. Specifically, in this case, the standard DInSAR nominal surface deformations without atmospheric corrections is intended to be compared with InSARICA method, referring exactly to the same data availability and period. This is to show one of the uses of InSAR-ICA technique, that is its capability of application in cases when no choices of data or ancillary different data availabilities are possible. 




Fig. 2. Differences between InSAR-ICA DEMs related to the period June-December 1995; the gray color ranges from maximum subsidence (black) to maximum uplifts (white). See text for more details.

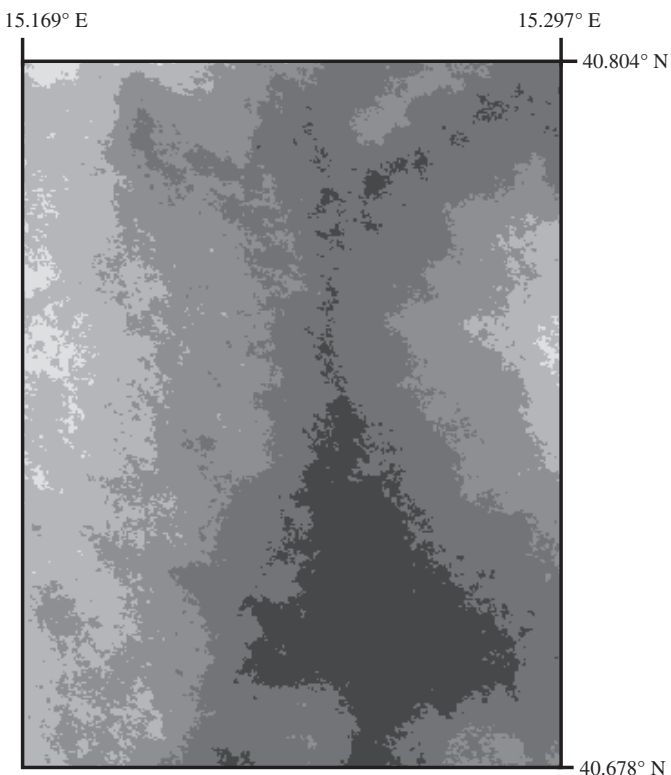

Fig. 3. Similar to fig. 2, but for the DInSAR nominal surface deformations.

\section{Observations}

The comparison between figs. 2 and 3 shows that in fig. 2 there is a more asymmetric distribution of the nominal maximum subsidences, which are located more on the western than on the eastern side of the river. Differently, fig. 3 shows a quite symmetric characterization on both sides of Sele. Therefore, the InSARICA DEM variations are in better agreement with expectations from previous ground based investigations (see paragraph 2), which indicate larger landslides and springs occurrence on the west side of Sele than on the east side (Agnesi et al., 1983; Carrara et al., 1986; Budetta et al., 1988).

This agreement is obtained for data and time period on which the corresponding DInSAR method would not give similar results. This is interpreted in terms of the capability of InSAR-ICA technique to provide useful DEM extraction in case of limited usability of atmospheric and ground data.

Although at the present status, the InSARICA DEMs-differences cannot represent precise quantitative surface deformations, it can be of interest to note that the darkest colour areas in fig. 2 include alluvial deposits, characterized by middle permeability, with typical landslide prone areas (e.g., Polemio and Petrucci, 2001) and the most stable zones correspond to typically stable high reliefs of limestone and dolomitic limestone (e.g., Wasowski et al., 2002).

Finally, the specific highest positive increases in elevations of fig. 2 are located over vegetated areas included in the Parco Regionale dei Monti Picentini on the west of Senerchia and the Riserva Naturale dei Monti EremitaMarzano on the east of Valva, possible associated with plants and trees growing during the summer season included between June and December 1995.

\section{Summary and Conclusions}

For an area of the Sele valley previous geological/hydrological observations indicate larger landslides and springs on the West side than on the East side of the river (see paragraph 2). 
According to the possible ERS SAR data availability during the period June-December 1995, the DInSAR standard method (without atmospheric corrections) is applied and the nominal surface deformations are derived. Their distribution over the area of study is not in good agreement with expectations as the deformations on the west are quite similar to those on the east of Sele. This indicates that over that specific period the DInSAR method cannot be routinely applied on the ERS SAR available data alone.

By using the same data available for the same period, two InSAR-ICA DEMs are derived for the time intervals June-August 1995 and September-December 1995. Their differences have not been validated to represent precise surface deformations, nevertheless they have to include these deformations, together with spurious artifacts.

Unlike DInSAR observations, the distribution of these InSAR-ICA DEM variations are in good agreement with previous geological/hydrological observations over the area of study, showing larger subsidences taking place on the west of Sele. This finding is interpreted in terms of the good precision of InSAR-ICA DEM in this specific case, with errors evidently smaller than expected or about equal in the two estimates and eliminated by their subtractions.

This case study confirms the usefulness of the InSAR-ICA method in circumstances of limited data availability and/or lack of ground based and meteorological ancillary data and supports the hypothesis of eventual possible extraction of surface deformations from differences between time-spaced InSAR-ICA DEMs.

\section{Acknowledgements}

ERS-1 and ERS-2 data are provided by European Space Agency in the context of the Category-1 Program, project n. 3193.

\section{REFERENCES}

Agnesi, V., A. Carrara, T. Macaluso, S. Monteleone, G. Pipitone and M. Sorriso Valvo (1983): Elementi tipologici e morfologici dei fenomeni di instabilità dei versanti indotti dal sisma del 1980 (alta valle del Sele), Geol. Appl. e Idrogeol., 18 (1), 309-341.

Ballatore, P. (2006): Synthetic Aperture Radar Interferometry: separation of atmospheric artifacts from effects due to the topography and the terrain displacements, Earth Planets and Space, 58, 927-935.

BALlatore, P. (2007): ICA technique applied to SAR interferometry, Proceedings of the Envisat Symposium 2007, Montreux, Switzerland, April 23-27 2007, European Space Agency, SP-636.

BALlatore, P. (2009): SAR interferometry: DEM estimations by Independent Component Analysis, to be submitted.

Budetta, P., P. Celico, A. Corniello, R. De Riso, D. DucCI and P. Nicotera (1988): Carta idrogeologica del F.186 (S. Angelo dei Lombardi) memoria illustrativa, Mem. Soc. Geol. It., 41, 1029-1038.

Carrara, A., V. Agnesi, T. Macaluso, S. Monteleone and G. PiPITONE (1986): Slope movements induced by the southern Italy earthquake of November 1980, Geol. Appl. e Idrogeol., 21 (2), 237-250.

Falorni, G., V. Teles, E.R. Vivoni, R.L. Bras and K.S. AmARATUNGA (2005): Analysis and characterizationof the vertical accuracy of digital elevation models from the Shuttle Radar Topography Mission, J. Geophys. Res., 110, F02005.

HANSSEN, R. (2001): Radar Interferometry, (Kluwer Academic Publishers, Dordrecht, The Netherlands).

HyvärinEN, A. and E. OJA (1997): Fast fixed-point algorithm for independent component analysis, Neural Comp., 9, 1483.

HyvÄRINEN, A., J. KARHUNEN and E. OJA (2001): Independent component analysis, (Wiley Interscience, New York, USA).

Polemio, M. and O. Petrucci (2001): Hydrological monitoring and image analysis of a mudslide in Southern Italy, Phys. Chem. Earth, 26, 689-695.

Wasowsky, J., V. Del Gaudio, P. Perri and D. CAPOLONGO (2002): Factors controlling seismic susceptibility of the Sele valley slopes: the case of the 1980 Irpinia earthquake re-examined, Survey of Geophysics, 23, 563-593.

(received February 2, 2009;

accepted March 25, 2009) 